\title{
From Self-Conceptions to Self-Worth: On the Sources and Structure of Global Self-Esteem
}

\author{
Brett W. Pelham and William B. Swann, Jr. \\ University of Texas at Austin
}

\begin{abstract}
Three factors were identified that uniquely contribute to people's global self-esteem: (a) people's tendencies to experience positive and negative affective states, (b) people's specific self-views (i.e., their conceptions of their strengths and weaknesses), and (c) the way people frame their self-views. Framing factors included the relative certainty and importance of people's positive versus negative self-views and the discrepancy between people's actual and ideal self-views. The contribution of importance to people's self-esteem, however, was qualified in 2 ways. First, importance contributed only to the self-esteem of those who perceived that they had relatively few talents. Second, individuals who saw their positive self-views as important were especially likely to be high in self-esteem when they were also highly certain of these positive self-views. The theoretical and therapeutic implications of these findings are discussed.
\end{abstract}

Max made his living robbing convenience stores. He never completed high school and spent a considerable portion of his adult life in a state penitentiary. Yet his pride and self-confdence revealed that he considered himself a capable, worthy person, easily on par with those employed in more respectable trades. Gene's was a very different story. After graduating Phi Beta Kappa from Harvard Law School, Gene became president of a large and successful law firm. Yet Gene continued to question his self-worth, as he had since his childhood. Plagued by worries and depression, one day he scribbled a note indicating that he regarded himself a failure and took his own life.

These hypothetical examples dramatize an important question: How do people move from specific knowledge of their abilities and accomplishments to global evaluations of their selfworth? The stories of Gene and Max suggest that self-esteem is not simply the product of some simple cognitive calculus that summarizes people's abilities and accomplishments. Conceivably, a more complex cognitive formula, one that incorporates the idea that some self-views are weighted more heavily than others, would offer a clearer insight into the origins of self-esteem. Alternatively, relatively undifferentiated "affective" (as compared with purely "cognitive") factors may play a role in self-esteem.

Our goal in this report is to better understand the cognitive and affective underpinnings of self-esteem. We begin by presenting a hypothetical model of the development of self-esteem,

This research and the preparation of this article were supported by a National Science Foundation graduate fellowship to Brett W. Pelham and by research funds (MH 37598) and a research scientist development award (MH 00498) to William B. Swann, Jr.

We are grateful to Jonathon Brown, Daniel Gilbert, Steve Gregorich, Douglas Krull, Alan Swinkels, Margaret Walsh, and Jason Young for their helpful comments on this research.

Correspondence concerning this article should be sent to Brett $W$. Pelham, who is now at the Department of Psychology, University of California, Los Angeles, California 90024. not because we intend to test it but simply as a means of organizing the components of self-esteem. This model suggests that several affective and cognitive variables differentially contribute to self-esteem at various points in people's lives. We assume, for example, that affective variables are particularly influential early in development.

\section{Affective Components of Self-Esteem}

Several developmental psychologists (Erikson, 1963; Sroufe, 1978) have emphasized the role of early affective experiences (e.g., treatment from a principle care giver) in determining an individual's sense of emotional well-being or self-worth. Before the development of a complex cognitive system capable of assessing specific beliefs about the self, children presumably learn that their environments are either friendly and satisfying or hostile and frustrating. Even very young infants, for example, seem to realize that they typically evoke either acceptance or disdain from others. Children presumably translate such early social experiences into a basic sense of pride or shame. This sense of worthiness may not only serve as the foundation of self-esteem, it may also influence the way adults later see themselves and their worlds (Rosenberg, 1986).

Watson and Clark (1984) have proposed that there are individual differences in the extent to which people experience positive and negative affective states. They suggested further that the predisposition to experience negative affective or emotional states (negative affectivity) should be distinguished from a tendency to experience positive affective or emotional states (positive affectivity). We attempt to measure these two forms of affectivity by using the measures recently developed by Watson, Clark, and Tellegen (1988). We expect that negative and positive affectivity may both be independently associated with self-esteem.

\section{Cognitive Components of Self-Esteem}

\section{Specific Self-Conceptions}

As children move beyond their preverbal years and develop belief systems, they form specific self-views that complement 
the relatively undifferentiated sense of self-worth developed earlier. As suggested by various classic perspectives on the self (e.g., Cooley's, 1902, notion of the "looking-glass self" and Festinger's, 1954, social comparison theory), people's specific selfviews should be related to their global self-esteem. Some researchers have even attempted to measure self-esteem by assessing a number of people's specific self-views and merely summing these measures.

Marsh (1986), for example, found that a composite of 12 multiple-item measures of people's specific self-views correlated better than .69 with global self-esteem. Still, despite the fact that it contained 136 items, Marsh's measure of people's self-views accounted for only about half of the variance in their global self-esteem. Thus, it appears that although self-esteem and specific self-views are strongly related, they are not equivalent (Hoge \& McCarthy, 1984; Rosenberg, 1979; Wylie, 1974). One reason for this may be that self-esteem is shaped by the manner in which people frame their specific self-views.

\section{Framing Factors}

Although people's self-views are probably the "building blocks" of self-esteem, the way people frame their particular self-views (i.e., the meaning they attach to them) should influence the ultimate impact of specific self-views on self-esteem. That is, individuals do not only ask themselves, "How good am I?" They also ask what it means to be good or bad at different things. The meaning a particular self-view has for people will be determined by their answer to several questions: (a) Is the attribute important to them? (b) how certain are they that they actually possess the attribute? and finally (c) how does their actual self-view compare with their ideal self-view?

Attribute importance. Almost by definition, self-views that are strongly linked to individuals' goals and values, those that they identify as more personally important, will be self-views that strongly influence their global sense of self-worth. Indeed, nearly a century ago, James (1890) suggested that abilities or identities on which people have "staked their salvation" should contribute significantly to self-esteem, whereas those to which people are less committed should have little impact on their perceptions of self-worth. Although this argument is intuitively appealing, empirical tests of James's notion have yielded mixed results. ${ }^{1}$

Rosenberg (1965) reported the first empirical test of James's (1890) proposal. He showed that individuals who possessed negative self-conceptions were more likely to be low in global self-esteem if they considered the negative characteristics personally important. He did not, however, report whether those who had positive self-views were especially likely to be high in global self-esteem if they considered the characteristics to be important. Also, many of the characteristics that Rosenberg measured were undoubtedly highly correlated (e.g., likable vs. well-liked by many different people). Thus, Rosenberg's pioneering study provided suggestive, but less than definitive, support for James's idea.

Moreover, attempts to replicate Rosenberg's (1965) findings have borne little fruit. Kaplan (1980), for example, found only weak support for the idea that personally important attributes have a disproportionate impact on global self-esteem. More up- setting yet, Hoge and McCarthy (1984) found that a measure that weighted individuals' specific self-conceptions by the personal importance of these self-conceptions actually correlated more poorly with self-esteem than did a simple additive measure of their self-conceptions.

Marsh (1986) provided a careful analysis of Hoge and McCarthy's (1984) approach to weighting participants' self-views and importance scores. Marsh argued that a true test of the hypothesis demands that researchers standardize participants' self-concept scores, ipsatize their importance scores, or both. Surprisingly, even when he took these steps, Marsh found only limited support for the idea that importance moderates the relation between specific self-views and global self-esteem. Therefore, despite the powerful intuitive appeal of James's (1890) arguments, even very'sophisticated studies have provided only weak support for his idea that self-conceptions on which people stake their being are highly influential determinants of self-esteem.

Can importance really be so unimportant? One reason why researchers have experienced such difficulty demonstrating a relation between importance and global self-esteem may be that they have failed to examine the intraindividual (i.e., idiographic) patterning of people's commitments to their self-conceptions. That is, past researchers have focused solely on the tendency of people to indicate that the dimensions on which they rank favorably relative to others (i.e., nomothetically) are particularly important to them. These rankings, however, have been inferred by the researchers on the basis of the average selfratings of the participants in their samples rather than on the self-ratings reported by participants themselves.

Assume, for example, that on a 10-point scale with a theoretical mean of 5.5, the actual average self-ratings for intellectual ability and artistic ability among college students are 7 and 3, respectively (that is, assume that most college students think that they are smarter than, but less artistically talented than, most of their peers). With this in mind, consider the woman who gives herself (a) a 6 (above average) on intellectual ability, (b) a 4 (below average) on artistic ability, and who reports (c) that intellectual ability is very important to her but (d) artistic ability is not. Even the most sophisticated weighting approaches used in previous research will penalize this woman on two counts. First, according to group averages, she appears to believe that she is below average in self-perceived intellectual ability and considers this ability very important. Second, she is taken to believe that she is above average in artistic ability and yet considers this ability unimportant. From the woman's point of view, however, she has reported that she is more talented intellectually than artistically and has also indicated that her intellectual talents are much more important to her than her artistic deficits!

This example suggests that the best way to conceptualize and measure importance is to focus on differential importance, that

\footnotetext{
'Although many past researchers have referred to importance as a measure of "self-concept salience," we conceptualize importance as a form of investment because it suggests a more stable orientation toward particular self-views and because it provides a framework for describing certainty as well as importance. The latter term also seems to be more in keeping with the spirit of James's (1890) original arguments.
} 
is, the amount of importance people impute to particular attributes relative to their other attributes. This idiographic approach to the manner in which individuals frame their selfviews applies to another important variable as well: the certainty of people's self-views.

Attribute certainty. The extent to which people are invested in their self-views will also be influenced by the extent to which they are certain of them. That is, as individuals gain experience in a domain relevant to their self-views, they become increasingly certain of those views, especially if the evidence they gather is consistent over time and across situations (e.g., Kelley, 1973; Pelham, 1989; Swann, in press). Logically, people will feel constrained to weigh self-views of which they are certain more heavily in assessing themselves than self-views of which they are uncertain.

The utility of distinguishing the certainty and importance of people's self-views can be illustrated through example. Consider the young man who for years has been pressured by his parents to become a violinist. A natural affinity for music and years of practice land him a position with the New York Philharmonic Orchestra. His self-conception as a musician is clearly quite positive, and he is quite certain of his ability as a musician. Yet he is miserable! His sense of self-worth may benefit only minimally from his musical talents because he considers music completely unimportant. Imagine further that, since his childhood, this same young man has maintained a secret ambition to become a mechanic. Although he believes that he has substantial mechanical aptitude, because of his limited experience in the area, he is quite uncertain of his potential as a mechanic. Again, his self-esteem may benefit only minimally from a very favorable self-view.

Finally, consider the young man's sister, a gifted athlete who considers both music and mechanics wholly unimportant. Ascribing a great deal of importance to athletics and feeling certain of her athletic talents, she may feel quite good about herself despite her shortcomings in music and mechanics. These examples suggest that only high levels of certainty and importance acting together can ensure that a specific self-conception will have considerable impact on self-esteem. One of our objectives is to test this possibility.

Self-ideal discrepancy. Another factor that may influence the relation between people's specific self-views and their global sense of self-worth is suggested by James's (1890) idea that selfesteem is equal to "success divided by pretension." To extend an earlier example, consider the woman who is quite certain of her athletic prowess and who considers athletic ability to be extremely important. Whether her position on the university track team guarantees her a position as a person of worth may depend heavily on her aspirations. Although making the university team may be a source of pride if this was her goal, it may only serve to depress her if she had hoped to secure a position on the Olympic team.

Half a century after James's (1890) prescient speculations, ego psychologists such as Horney (1945) and especially Rogers (1951) prompted research addressing the relation between individuals' self-views and their pretensions or idealized self-views (e.g., Butler \& Haigh, 1954, Katz \& Zigler, 1967; see also Higgins, 1987, and Markus \& Nurius, 1986, for contemporary extensions of this issue). Researchers have typically studied the ideal self by asking individuals to report their actual and their idealized self-views and inferring a "self-ideal discrepancy" from these two measures, typically by means of difference scores. Unfortunately, this approach has theoretical and methodological problems (e.g., see Cronbach \& Furby, 1970, and especially Wylie, 1974, 1979): problems that could explain the fact that the self-ideal discrepancy has little or no effect beyond that provided by individuals' actual self-views (e.g., Altrocchi, Parsons, \& Dickoff, 1960; Guerney \& Burton, 1967; Kubiniec, 1970).

In keeping with our emphasis on the individual's subjective frame of reference, we assume here that the best measure of the discrepancy between people's real and ideal self-views is one that is provided by individuals themselves (rather than inferred by the researcher). We designed our measure of self-ideal discrepancy with this assumption in mind.

Interactive predictors of self-esteem. Researchers who have explored the relation of self-views and global self-esteem previously have emphasized the potential role of importance of people's self-views. For example, some researchers have attempted to develop a simple weighted score (an index giving greater weight to more important self-conceptions), with the idea being that it should correlate more strongly with global self-esteem than should the unweighted composite from which it was derived. Despite the intuitive appeal of this approach, we believe that there are some important advantages to separating rather than combining the various components of self-esteem (see Marsh, 1986, for a related discussion). It is possible, for example, that differential importance bears a different relation to the self-esteem of those who possess many versus few selfperceived talents. Similarly, it also seems possible that differential certainty and differential importance working together might make an especially strong contribution to global self-esteem. By distinguishing differential importance from our other variables, and focusing particularly on interactions involving this variable, we hoped to better understand the relation between this variable and self-esteem. In so doing, we also hoped to answer some preliminary questions about the structure of self-esteem.

\section{Summary}

In this investigation, we wanted to examine the contribution of three factors to self-esteem: (a) people's negative and positive affective states, (b) people's specific self-views, and (c) the manner in which people framed their self-views (in terms of importance, certainty, and the self-ideal discrepancy). Finally, we also wanted to see if the subjective importance of people's self-views might interact with any of the other variables in predicting global self-esteem.

\section{Method}

\section{Participants}

Undergraduates at the University of Texas at Austin (245 men and 256 women) participated in this research for credit in their introductory psychology course. Fifteen participants were deleted from the sample because they completed the questionnaires improperly. This left a total of 486 participants in the study. 


\section{Overview of Procedure}

Participants took part in this questionnaire study in groups of 8 to 60 individuals. A male experimenter introduced the investigation as a study of people's personalities and their attitudes about themselves and their daily activities. Participants completed some background items and (a) Rosenberg's (1965) Global Self-Esteem Scale, (b) Watson et al.'s (1988) measures of positive and negative affectivity (the Positive and Negative Affect Schedule, or PANAS), (c) a 10-item version of the SelfAttributes Questionnaire (SAQ, including separate certainty and importance measures based on the $10 \mathrm{SAQ}$ attributes), and (d) a self-ideal discrepancy measure (also based on the SAQ). A number of measures relevant to a separate investigation (see Swann \& Pelham, 1989) were interspersed between these measures.

\section{Questionnaire Measures}

Global self-esteem. Our measure of global self-esteem was Rosenberg's (1965) 10-item scale. Typical items include "I feel that I am a person of worth, at least on an equal basis with others," "All in all, I'm inclined to feel that I am a failure," and "On the whole, I am satisfied with myself." We modified the scale slightly by expanding the 4-point format to a 5-point Likert scale and recoding negatively worded items to produce a single score. The scale responses proved to be internally consistent $(\alpha=.82)$.

Measures of negative and positive affectivity. We used Watson et al.'s (1988) PANAS to tap the affective components of self-esteem. Participants reported (on 5-point Likert scales) the extent to which they had experienced 10 positive emotions (e.g., inspired, interested, and strong) and 10 negative emotions (e.g., hostile, afraid, and jittery) during the past week. One item from each scale ("proud" from the positive scale and "ashamed" from the negative scale) was deleted because of its surface resemblance to the global self-esteem measure. Coefficient alpha for the resulting measures of negative and positive affectivity was high (.86 and .87 , respectively).

The $S A Q$. Our measure of specific self-conceptions was the 10-item version of the SAQ. This scale tapped people's self-views on 10 valenced attributes such as intellectual capability, physical attractiveness, leadership ability, and emotional stability. For each of the $10 \mathrm{SAQ}$ attributes, participants rated themselves as compared with other college students their own age on scales ranging from 1 (bottom 5\%) to 10 (top 5\%). The precise wording of the SAQ can be found in the appendix.

The short (5-item) version of the SAQ has been shown to be stable over a period of 4 months, test-retest $r(50)=.77$. Also, the 10 -item version proved to be internally consistent $(\alpha=.76)$. Participants' responses to this scale were thus summed to form a composite measure of their specific self-views. After reporting their self-views, participants indicated the certainty of each of the 10 self-views on scales ranging from 1 (not at all certain) to 9 (extremely certain). Next, participants rated the extent to which each SAQ attribute was personally important to them on similar 9-point scales.

Indexes of differential certainty and importance. A differential certainty index was computed for each participant by treating each of his or her specific self-ratings as a "predictor" observation and each corresponding certainty rating as a "criterion" observation in the computation of a within-subjects correlation coefficient. A participant's differential certainty index was the correlation between his or her specific selfratings and the certainty of these self-ratings. Thus, individuals received high scores on this index to the extent that their more positive self-views were those of which they were most certain. Except for the substitution of importance ratings for certainty ratings, this approach was duplicated in the computation of a differential importance index for each participant. Twenty-two individuals gave themselves precisely the same rating on all $10 \mathrm{SAQ}$ items, or on the associated certainty or importance ratings, making it impossible to compute a differential certainty or im- portance index. Thus, data from these participants could not be analyzed. This left a total of 464 participants in the sample.

Self-ideal discrepancy measure. Participants provided a measure of the discrepancy between their actual and ideal self-views by rating themselves on each dimension of the SAQ relative to their ideal selves, that is, "relative to the person you would be if you were exactly the way you would like to be." The scale used for this purpose ranged from 1 (very short of my ideal self) to 9 (very much like my ideal self). A five-item version of the self-ideal discrepancy measure has been shown to be temporally stable (test-retest $r[51]=.75$ over a 16 -day period) and participants' responses to the extended measure used in this research proved to be internally consistent ( $\alpha=.85$ ). Thus, participants' scores on this measure were summed to form a composite measure of the discrepancy between their actual and ideal self-views. Descriptive statistics for the measures used in this research appear in Table 1. Table 1 also contains a matrix of the intercorrelations among these measures.

\section{Results and Discussion}

We expected that each of the six variables identified as potential components of self-esteem would make a unique contribution to self-esteem. We also expected that differential importance might interact with the other cognitive components of self-esteem. In particular, we tested for interactions between differential importance and (a) people's specific self-views, (b) differential certainty, and (c) the discrepancy between people's actual and ideal self-views. ${ }^{2}$

\section{Unique Predictors of Self-Esteem}

To see which specific variables would contribute uniquely to self-esteem, we conducted a simultaneous multiple regression in which the criterion variable was global self-esteem and the predictors were (a) negative affectivity, (b) positive affectivity, (c) participants' SAQ scores, (d) differential importance, (e) differential certainty, and (f) the self-ideal discrepancy measure. As illustrated in Table 2, all of these variables accounted for a unique portion of the variance in global self-esteem.

Despite the relatively large size of our sample, we suspect that the beta weights displayed in Table 2 provide nothing more than a very rough approximation of the relative contribution of the variables listed. After all, the relatively high loadings for the measure of people's self-conceptions and the measures of positive and negative affect may simply reflect the higher reliability of these measures. The differential importance and differential certainty measures, for example, cannot be more reliable than the measure of self-conceptions from which they are derived. Thus, the fact that the framing measures account for less variance than the other measures may have more to do with psychometrics than psychologic. The important point is that each of the six variables considered made some unique contribution to self-esteem. It appears, then, that global self-esteem is related not only to individuals' specific self-views, but also to more rudimentary affective factors and to more sophisticated framing factors.

\footnotetext{
${ }^{2}$ Gender had no main or interactive effects on our dependent measures.
} 
Table 1

Relations Among the Predictors of Self-Esteem

\begin{tabular}{|c|c|c|c|c|c|c|c|c|c|}
\hline Predictor & $M$ & $S D$ & Theoretical range & 1 & 2 & 3 & 4 & 5 & 6 \\
\hline 1. Composite self-views & 67.5 & 9.778 & $10-100$ & - & & & & & \\
\hline 2. Negative affectivity & 20.0 & 7.209 & $9-45$ & -.331 & - & & & & \\
\hline 4. Differential importance & 0.54 & 0.283 & $-1.0-+1.0$ & .077 & -.124 & .100 & - & & \\
\hline 5. Differential certainty & 0.40 & 0.418 & $-1.0-+1.0$ & .302 & -.159 & .139 & .082 & - & \\
\hline 6. Self-ideal discrepancy & 63.7 & 13.703 & $10-90$ & .385 & -.188 & .323 & .066 & .172 & - \\
\hline
\end{tabular}

Note. Correlations and descriptive statistics are based on the 464 participants included in major analyses reported in the text. All $r>.09$ were reliable at $p<.05$.

\section{Interactive Predictors of Self-Esteem}

We were also interested in the interactive predictors of selfesteem. In particular, we expected that the relation between differential importance and self-esteem might vary at different levels of the other cognitive predictors. To test this idea, we conducted a regression analysis of variance (a regression ANOVA) to see whether interactions between differential importance and (a) individuals' self-views, (b) differential certainty, and (c) the self-ideal discrepancy would make a unique additional contribution to self-esteem. Thus, in this simultaneous regression analysis, we entered the six predictors from the previous analysis as well as the three differential importance interaction terms just listed. This analysis indicated that the relation between differential importance and self-esteem does differ at different levels of the other variables considered.

First, there was a reliable interaction between differential importance and people's specific self-views, $F(1,454)=5.91, p=$ .015. As illustrated in the upper half of Table 3, regressionbased simple effects tests revealed that whereas differential importance was unrelated to the self-esteem of participants with relatively positive or even moderate self-views $(F \mathrm{~s}<1.0$ and 1.4 , respectively), it was clearly associated with self-esteem for participants with relatively negative self-views, $F(1,164)=$ $10.71, p=.001$. Apparently, if individuals are convinced that they have a great number of talents, it is not necessary for them to believe that their greatest talents are also those that are most important to them. Alternatively, for individuals who do not see themselves as especially talented in most areas, attributing great importance to their favorable attributes appears to have substantial impact on their self-esteem.

Differential importance also interacted with differential certainty, $F(1,454)=5.02, p=.026$. As can be seen in the lower half of Table 3 , the relation between differential importance and self-esteem was stronger at higher levels of differential certainty. Regression-based simple effects tests supported this interpretation. Specifically, differential importance was unrelated to the self-esteem of individuals low in differential certainty $(F<2.2$, $n s$ ), was modestly related to the self-esteem of individuals who were neither high nor low in differential certainty, $F(1,152)=$ $4.40, p=.038$, and was strongly associated with self-esteem in individuals high in differential certainty, $F(1,153)=13.97, p<$ .001 . It appears, then, that those who are highly certain of their positive self-views and who also consider these views especially important are especially likely to enjoy the benefits of high selfesteem.
Finally, there was some weak evidence that the relation between differential importance and self-esteem is especially high among individuals who feel that they fall somewhat short of their ideal self-views, $F(1,454)=2.76, p=.098$. This interaction was not reliable, however, and should be treated cautiously.

\section{The Importance of Importance}

Given the focus of past research on understanding the relation between global self-esteem and importance and the abundance of weak or null findings on the issue, it seemed instructive to examine more closely the relation between importance and self-esteem. As noted in the preceding section, two of the three analyses performed suggest that importance is strongly associated with self-esteem in some individuals yet only weakly associated for others. Specifically, the Differential Importance $X$ Self-View interaction indicates that importance is related only to the self-esteem of individuals with relatively negative selfviews. Similarly, the Differential Importance $\times$ Differential Certainty interaction suggests that importance is a strong predictor of self-esteem only for individuals who are relatively certain of their more positive self-views. Importance should be most closely associated with self-esteem, then, for individuals who possess a greater than average number of negative selfviews and yet are highly certain of their more favorable selfviews. This appears to be the case. For individuals whose overall self-views were somewhat negative and for whom the differential certainty index was relatively high, the correlation between differential importance and self-esteem was $r(35)=.61, p<$ .001 . Because this correlation holds individuals' self-views and differential certainty approximately constant, it is the rough equivalent of a partial correlation. A true partial correlation between differential importance and self-esteem (controlling simultaneously for the effects of the other three variables-the self-ideal discrepancy and the two affective measures) yielded even stronger results, $r(32)=.70, p<.001$ (overall $R=.85$, adjusted $R^{2}=.69$ ). Thus, whereas differential importance made only a modest contribution to the self-esteem of many participants, for some participants this variable accounted for almost one half of the unique variance in their self-esteem. Besides suggesting an important reason that past researchers have had such difficulty obtaining the elusive "importance effect," the interactions contributing to this finding also shed light on the structure of self-esteem. 
Table 2

Components of Self-Esteem

\begin{tabular}{lcrc}
\hline \multicolumn{1}{c}{ Variable } & Zero-order $r$ & $\beta$ & \multicolumn{1}{c}{$p$} \\
\hline 1. Negativity affectivity & -.497 & -.29 & $<.001$ \\
2. Composite self-views & .496 & .26 & $<.001$ \\
3. Positive affectivity & .467 & .22 & $<.001$ \\
4. Differential importance & .217 & .13 & $<.001$ \\
5. Self-ideal discrepancy & .323 & .08 & $<.05$ \\
6. Differential certainty & .256 & .08 & $<.05$ \\
\hline
\end{tabular}

Note. Variables are listed in decreasing order of their unique contribution to self-esteem. For all zero-order $r$, $p<.001 ; R=.67, p<.001$.

\section{Alternative Approaches to Importance}

These data indicate that importance played a potent role in the self-esteem of some of our participants. It is possible, however, that the effects observed have more to do with our particular sample and measures rather than with our particular conceptual approach. To address this issue, we conducted a number of more conventional analyses patterned directly after past approaches to this question (these approaches are discussed in greater detail in Marsh, 1986). First, we computed four separate indexes giving greater weight to individuals' more important self-views. These four indexes included all possible combinations of raw (untransformed) versus standardized self-ratings and raw versus ipsatized importance ratings. These analyses yielded results quite similar to those reported by Marsh. For example, the weighted measure based on both raw self-concept ratings and raw importance scores correlated somewhat more poorly with self-esteem than did the unweighted composite of self-ratings $(r=.46 \mathrm{vs} . .50)$. In addition, each of the three more sophisticated weighting systems produced correlations that were virtually identical to the unweighted correlation (both correlations involving ipsatized importance scores were .50 , and the correlation involving standardized self-ratings and raw importance scores was .49). Similarly, a regression-based ANOVA involving (a) individuals' composite self-ratings, (b) a composite (summary) importance measure, and (c) a Self-Rating $\times$ Importance interaction term revealed no main or interactive effects of the composite importance ratings (both $F \mathrm{~s}<1.0$ ).

Traditional analyses focusing on single items also offered little evidence for a unique contribution of importance to selfesteem. A regression analysis that included all 10 specific selfratings, all 10 importance ratings, and 10 Self-Rating $\times$ Importance interaction terms revealed only one marginally reliable interaction. Also, 10 separate analyses focusing individually on particular SAQ attributes revealed only one reliable SelfRating $\times$ Importance interaction. These analyses thus suggest that our approach offers insights into the components and structure of global self-esteem that are not offered by previous approaches.

\section{General Discussion}

Historically, there has been some disagreement about exactly what constitutes self-esteem. Some have conceptualized self-es- teem as a global feeling state applied to the self; others have argued that self-esteem is a purely cognitive abstraction. Our findings suggest that both perspectives capture a portion of reality. That is, it appears that people's general sense of self-worth is determined by three distinct factors: (a) their positive and negative feelings about themselves, (b) their specific beliefs about themselves, and (c) the way that they frame these beliefs.

One implication of our findings is that it may be useful to measure not only people's self-views but also the way they frame their self-views. Apparently, two individuals who receive the same score on a measure of specific self-views may have selfconcepts with quite different structures. Such differences may have consequences for issues other than self-esteem. Swann and Ely (1984) and Swann, Pelham, and Chidester (1988), for example, have shown that people who are highly certain of their beliefs are more likely to resist efforts to change these beliefs. Similarly, Pelham (1989) has found that individuals showed a higher test-retest correlation on their "most certain" as compared with "least certain" SAQ self-views. The importance of people's beliefs about themselves, on the other hand, predicts very different behaviors, such as the likelihood that individuals will seek information about their beliefs or the accuracy of people's judgments about others (Pelham \& Swann, 1989; Swann \& Pelham, 1989)-findings reminiscent of Markus's (1977) work on schematicity.

Our findings not only suggest that there are substantial individual differences in the structure of the self-concept (e.g., individual differences in differential importance); they also suggest that the same structural variable may have very different consequences for different individuals (e.g., those who have many vs. few self-perceived talents). The structure of the self-concept, even for a single individual, may also vary over the course of the life span. We suggested earlier, for instance, that affect plays a disproportionate role in the self-esteem of younger people. Similarly, Rosenberg (1979) has suggested that the discrepancy between individuals' actual and ideal self-views may take on special prominence during adulthood. Each of these possibilities seems worthy of future investigation.

By suggesting that self-esteem is multiply determined and complex in its organization, our findings also attest to the inade-

Table 3

Interactive Predictors of Self-Esteem

\begin{tabular}{|c|c|c|c|c|c|c|}
\hline \multirow[b]{3}{*}{ Predictor } & \multicolumn{6}{|c|}{ Differential importance } \\
\hline & \multicolumn{2}{|c|}{ Low } & \multicolumn{2}{|c|}{ Moderate } & \multicolumn{2}{|c|}{ High } \\
\hline & $M$ & $n$ & $M$ & $n$ & $M$ & $n$ \\
\hline \multicolumn{7}{|c|}{ Composite self-view } \\
\hline Negative & 34.8 & 70 & 35.3 & 52 & 39.3 & 44 \\
\hline Moderate & 40.2 & 43 & 40.7 & 48 & 41.5 & 59 \\
\hline Positive & 42.6 & 41 & 42.7 & 56 & 43.3 & 51 \\
\hline \multicolumn{7}{|c|}{ Differential certainty } \\
\hline Low & 37.5 & 58 & 37.4 & 45 & 39.4 & 52 \\
\hline Moderate & 39.1 & 55 & 40.6 & 55 & 41.6 & 44 \\
\hline High & 38.8 & 41 & 40.4 & 56 & 43.2 & 58 \\
\hline
\end{tabular}

Note. Higher numbers indicate higher self-esteem. Theoretical range is $10-50$, sample mean $=39.8, S D=6.46$. 
quacy of any single extant theory of the origins of self-esteem. All of the variables included in this study made an independent contribution to self-esteem. Our findings also suggest that selfesteem may be an interactive function of some of these variables. The connection between differential importance and selfesteem, for example, appears to depend on both the nature of individuals' self-views and the differential certainty of these selfviews.

\section{Therapeutic Implications}

Our findings may also have important practical implications. The interactions involving people's specific self-views and differential importance, for example, have implications for cognitive therapies designed to improve people's self-esteem. These findings suggest that whereas convincing individuals with negative self-views to accept themselves for what they are may produce some improvement in their self-esteem, convincing individuals with predominantly negative self-views to appreciate the importance of their more positive self-views should be an especially effective method of raising their self-esteem.

The idea that self-esteem has relatively independent cognitive and affective components also has important implications for therapies designed to bolster self-esteem. In essence, strictly cognitive therapies treat only half of the "malady" of low selfesteem. What is needed are therapies that address both cognitive and affective aspects of low self-esteem. Some recent developments in cognitive therapy reflect an implicit appreciation for such an approach. Hollon and Garber (1986), for example, have suggested that cognitive and behavioral therapies (e.g., success therapies) be combined in the treatment of depression. By attacking low self-esteem on both cognitive and affective fronts, therapists should greatly increase the chances of successful treatment.

Just as our data have implications for therapy designed to bolster self-esteem, they may also have implications for the ways that healthy people maintain their positive global self-evaluations. Recent research (e.g., Alloy \& Abramson, 1979; Campbell, 1986; Taylor \& Brown, 1988) has challenged traditional views of mental health by identifying a number of optimistic biases that happy, mentally healthy individuals use in the service of maintaining their psychological well-being. Taylor and Brown, for example, described one such optimistic bias as an overly generous appraisal of one's talents and abilities. Although we do not deny the existence of such biases and distortions, there are surely some practical limits to developing unrealistically positive views of our abilities. Our findings suggest, however, that people might bolster their self-esteem in a manner that requires no distortion whatsoever-that is, by framing their specific self-views in a manner that is favorable to themselves. Thus, although the proverbial $98-\mathrm{lb}$ weakling might be unable to convince others that he is the next Mr. Olympia, he is completely free to decide that an Olympian physique is of little importance to him. In this way, he may concede his wimpiness without experiencing any damage to his self-esteem.

Finally, our research also attests to the importance of an integrative, idiographic approach to the study of the self. For students of the self, the complexity of its structure and components represents a significant barrier to understanding. Whatever the components of the self might be, however, it is clear that they derive in large part from social experience and that individuals fit them together to form a meaningful, integrated whole. It also seems likely that the structure of these components might vary systematically over the course of the life span. Simply put, it appears that each of three schools of psychology-social, developmental, and personality - have unique lessons to teach about the self. If we wish to understand the self completely, it appears that we must enroll in them all.

\section{References}

Alloy, L. B., \& Abramson, L. Y. (1979). Learned helplessness, depression, and the illusion of control. Journal of Experimental Psychology: General, 108, 441-485.

Altrocchi, J., Parsons, O. A., \& Dickoff, H. (1960). Changes in self-ideal discrepancy in repressors and sensitizers. Journal of Abnormal and Social Psychology, 61, 67-72.

Butler, J. M., \& Haigh, G. V. (1954). Changes in the relation between self-concepts and ideal self-concepts consequent upon client-centered counseling. In C. R. Rogers \& R. F. Dymond (Eds.), Psychotherapy and personality change (pp. 55-75). Chicago: University of Chicago Press.

Campbell, J. D. (1986). Similarity and uniqueness: The effects of attribute type, relevance, and individual differences in self-esteem and depression. Journal of Personality and Social Psychology, 50, 281294.

Cooley, C. H. (1902). Human nature and the social order. New York: Scribner's.

Cronbach, L. J., \& Furby, L. (1970). How should we measure "change"?-or should we? Psychological Bulletin, 74, 68-80.

Erikson, E. H. (1963). Childhood and society (2nd ed.). New York: Norton.

Festinger, L. (1954). A theory of social comparison processes. Human Relations, 7, 117-140.

Guerney, B., Jr., \& Burton, J. L. (1967). Comparison of typical peer, self, and ideal percepts related to college achievement. Journal of Social Psychology, 73, 253-259.

Higgins, E. T. (1987). Self-discrepancy: A theory relating self and affect. Psychological Review, 94, 319-340.

Hoge, D. R., \& McCarthy, J. D. (1984). Influence of individual and group identity salience in the global self-esteem of youth. Journal of Personality and Social Psychology, 47, 403-414.

Hollon, S. D., \& Garber, J. (1986). Cognitive therapy: A social-cognitive perspective. In L. Y. Abramson (Ed.), Social-personal influences in clinical psychology. New York: Guilford Press.

Horney, K. (1945). Our inner conflicts. New York: Norton.

James, W. (1890). The principles of psychology. New York: Holt.

Kaplan, H. B. (1980). Deviant behavior in defense of self. New York: Academic Press.

Katz, P., \& Zigler, E. (1967). Self-image disparity: A developmental approach. Journal of Personality and Social Psychology, 5, 186-195.

Kelley, H. H. (1973). The process of causal attribution. American Psychologist, 28, 107-128.

Kubiniec, C. M. (1970). The relative efficacy of various dimensions of the self-concept in predicting academic achievement. American Educational Research Journal, 7, 321-336.

Markus, H. (1977). Self-schemata and processing information about the self. Journal of Personality and Social Psychology, 35, 63-78.

Markus, H., \& Nurius, P. (1986). Possible selves. American Psychologist, 41, 954-969.

Marsh, H. W. (1986). Global self-esteem: Its relation to specific facets of self-concept and their importance. Journal of Personality and Social Psychology, 51, 1224-1236. 
Pelham, B. W. (1989). On confidence and consequence: The certainty and importance of self-knowledge. Unpublished doctoral dissertation, University of Texas at Austin.

Pelham, B. W., \& Swann, W. B., Jr., (1989). [Self-perception, socialperception, and investment: Epimotive versus schematic social information-processing.] Unpublished raw data, University of Texas at Austin.

Rogers, C. R. (1951). Client-centered therapy: Its current practice, implications, and theory. Boston: Houghton Mifflin.

Rosenberg, M. (1965). Society and the adolescent self-image. Princeton: Princeton University Press.

Rosenberg, M. (1979). Conceiving the self. New York: Basic Books.

Rosenberg, M. (1986). Self-concept from middle childhood through adolescence. In J. Suls \& A. G. Greenwald (Eds.), Psychological perspectives on the self( Vol. 3). Hillsdale, NJ: Erlbaum.

Sroufe, L. A. (1978). Attachment and the roots of competence. Human Nature, 1, 50-57.

Swann, W. B., Jr. (in press). To be adored or to be known?: The interplay of self-enhancement and self-verification. In R. M. Sorrentino \& E. T. Higgins (Eds.), Handbook of motivation and cognition (Vol. 2). New York: Guilford.
Swann, W. B., Jr., \& Ely, R. J. (1984). A battle of wills: Self-verification versus behavioral confirmation. Journal of Personality and Social Psychology, 47, 1287-1302.

Swann, W. B., Jr., \& Pelham, B. W. (1989). Accuracy in ongoing social relationships. Manuscript in preparation.

Swann, W. B., Jr., Pelham, B. W., \& Chidester, T. R. (1988). Change through paradox: Using self-verification to alter beliefs. Journal of Personality and Social Psychology, 54, 268-273.

Taylor, S. E., \& Brown, J. D. (1988). Illusion and well-being: A social psychological perspective on mental health. Psychological Bulletin, 103, 193-210.

Watson, D., \& Clark, A. L. (1984). Negative affectivity: The disposition to experience aversive emotional states. Psychological Bulletin, 96 . 465-490.

Watson, D., Clark, L. A., \& Tellegen, A. (1988). Development and validation of brief measures of positive and negative affect: The PANAS scales. Journal of Personality and Social Psychology, 54, 1063-1070.

Wylie, R. C. (1974). The self-concept (rev. ed., Vol. 1). Lincoln: University of Nebraska Press.

Wylie, R. C. (1979). The self-concept (rev. ed., Vol. 2). Lincoln: University of Nebraska Press. 
Appendix

The Self-Attributes Questionnaire

This questionnaire has to do with your attitudes about some of your activities and abilities. For the first ten items below, you should rate yourself relative to other college students your own age by using the following scale:

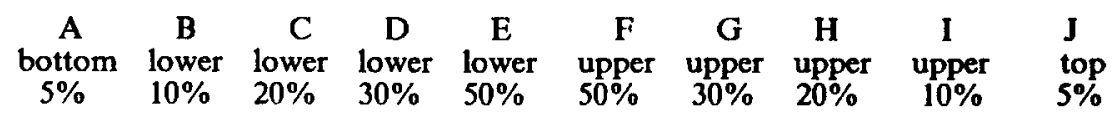

An example of the way the scale works is as follows: if one of the traits that follows were "height", a woman who is just below average in height would choose " $\mathrm{E}$ " for this question, whereas a woman who is taller than $80 \%$ (but not taller than $90 \%$ ) of her female classmates would mark " $\mathrm{H}^{\prime \prime}$, indicating that she is in the top $20 \%$ on this dimension.

1. intellectual/academic ability

2. social skills/social competence

3. artistic and/or musical ability

4. competency or skill at sports

5. physical attractiveness

6. leadership ability

7. common sense

8. emotional stability

9. luck

10. discipline

Now rate how certain you are of your standing on each of the above traits (you may choose any letter):

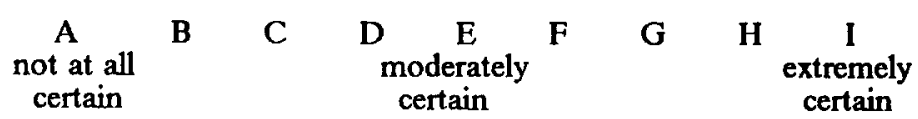

11-20. (same as items 1-10)

Now rate how personally important each of these domains is to you:

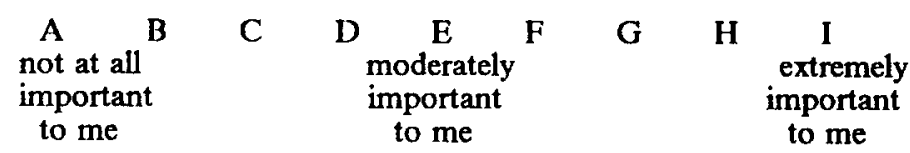

21-30. (same as items 1-10)

Now rate yourself relative to your "ideal" self -- the person you would be if you were exactly the way you would like to be:

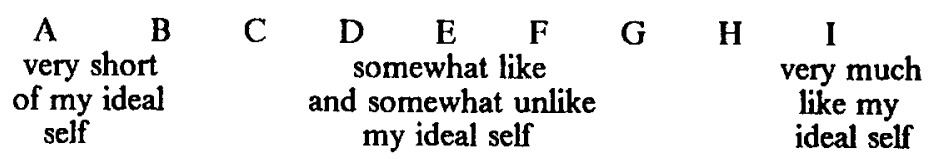

31-40. (same as items 1-10)

Note. In more recent versions of the SAQ, item 4 has been reworded to read "athletic ability," and item 9 has been replaced with "sense of humor." The short version of the SAQ makes use of items 1-5 only. 